\title{
OPF for an HVDC feeder solution for railway power supply systems
}

\author{
J. Laury, L. Abrahamsson \& S. Östlund \\ KTH, Royal Institute of Technology, Stockholm, Sweden
}

\begin{abstract}
With increasing railway traffic, the demand for electrical power increases. However, railway power systems are often weak causing high transmission losses and large voltage drops.

One possible method for strengthening the railway power supply system is to implement a High Voltage Direct Current (HVDC) feeder in parallel to the Overhead Contact Line (OCL). The HVDC feeder is connected to the OCL by converters.

This paper describes different properties and characteristics of such an HVDC feeder solution. An AC/DC unified Optimal Power Flow (OPF) model and unit commitment is used to obtain proper control of the converters.

The non-linear load flow and converter loss equations, and the binary variables for the unit commitment, lead to an optimization problem of Mixed Integer NonLinear Programming (MINLP) type. The optimization problem is formulated in the software GAMS, and is solved by the solver BONMIN. In each case, the objective has been to minimize the total active power losses.
\end{abstract}

Keywords: HVDC, MINLP, OPF, railway, unit commitment, load flow.

\section{Introduction}

Today, most rail power systems are weak, causing high transmission losses and large voltage drops. Furthermore, the railway traffic is increasing and more power is required from the Railway Power Supply System (RPSS). Therefore, there is an identified need for a technical solution to fulfill the increased power demand and to reduce the high transmission losses.

Most of the catenary systems in service have high impedance causing high transmission losses. In addition, voltage levels at the Overhead Contant Line 
(OCL) can drop significantly. To improve the voltage levels at the OCL and reduce the transmission losses, additional High Voltage Altering Current (HVAC) feeders have been installed and proven to be cost efficient where used according to [1]. However, the utilization of such a solution requires a high level of land usage around the rail which is difficult to obtain, especially in densely populated areas. Furthermore, the material usage is high, e.g. transformers having a weight of 70 tons have to be used.

The concept of an RPSS fed through optimally controlled HVDC converters has been presented in [2]. The proposed converter technology for the HVDC feeder solution uses medium frequency transformers, in order to reduce the size of the converter [3]. If smart control is applied to the converters, the total installed power for a railway section can be reduced. The HVDC cables can be buried along the railway requiring less land usage than HVAC overhead lines, and the cable capacitances do not impose the same constraints for DC as for AC.

This paper follows the ideas of [2], were the HVDC feeder solution was investigated for an RPSS equipped with OCL with Booster Transformers (BT). However, this paper compares transmission losses and voltage levels for:

- OCL with BT and Auto Transformers (AT) systems.

- Trains operating at power factor 0.8, 0.9 and 1 .

- Varied converter size and spatial distribution.

The OPF HVDC feeder solution is formulated as an optimization problem where the objective is to minimize the overall active power losses. However, the solutions in the studied cases are only valid for a specific time instance, since in real-life the consumptions and locations of the trains will vary over time. Thus, the solutions presented sets a theoretical upper bound on how small the losses can be given a specific time instance, if smart control is applied on the converters.

\section{Background}

Low-frequency RPSS can typically be fed in two ways: Decentralized System (DS) layout or Centralized System (CS) layout. The CS layout has an additional feeder, in Sweden at $132 \mathrm{kV}, 16 \frac{2}{3} \mathrm{~Hz}$, that is connected in parallel with the OCL, as shown in Figure 1. The transformers used to connect the OCL and the HVAC feeder line are rated at $16 \mathrm{MVA}$ and $25 \mathrm{MVA}$.

The DS does not have any HVAC feeder, and is used in areas where it is either not economically motivated or there are societal barriers. Figure 2 presents the system layout of the decentralized system.

Common for both systems, is that they are fed via converters. These converters are placed individually, or in groups in a converter station. The distance between the converter station is in the range of 40-200 km, and the number of converters in a converter station depends on the power demand. However, the converters are not optimally controlled, and the static converters are set to mimic rotary converters $[4,5]$. 


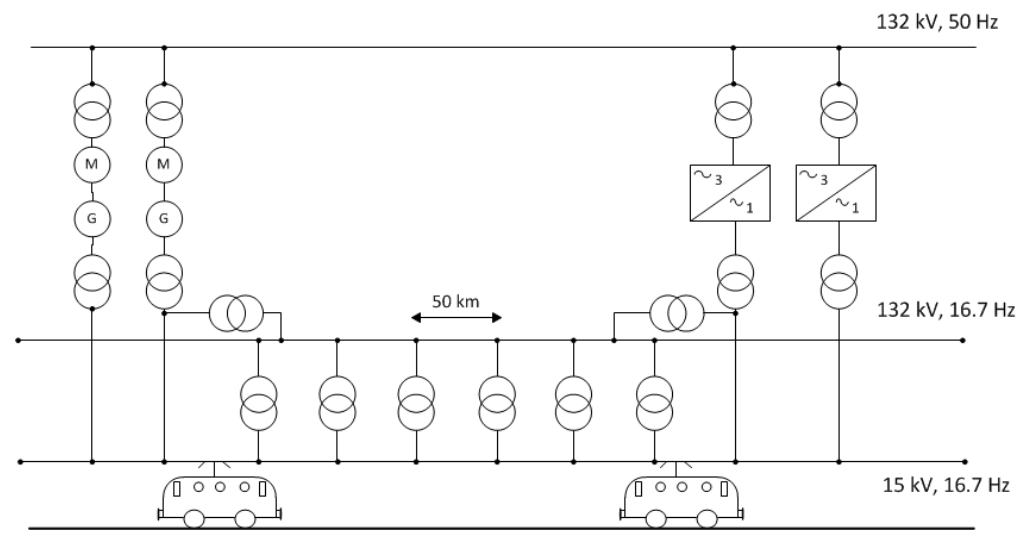

Figure 1: Centralized feeder system layout.

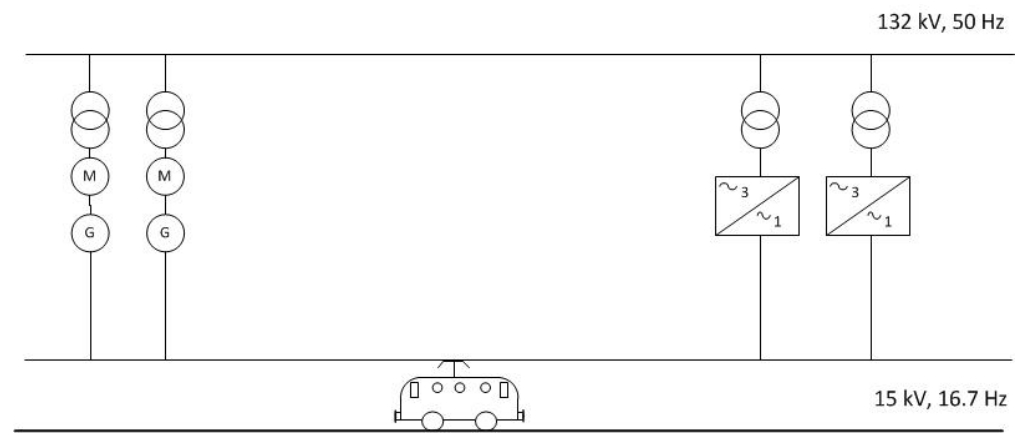

Figure 2: Decentralized feeder system layout.

\section{Models}

\subsection{HVDC converter}

From a system point of view, the converter is divided into an AC side and a DC side. The DC side of the converter unit is connected to the supplying DC grid and the AC side is connected to the AC grid, that is the OCL.

The converter unit can operate both in rectifier mode and inverter mode, allowing active power to flow in both directions. Reactive power production is dependent on the AC side voltage of the converter, and is limited by equations (5) and (6). Equation (2) defines the apparent power of the converter unit. If the voltage at the AC side of the converter drops, the converter apparent power output is reduced as described by (1). The active power input/output of the converter unit is defined by equations (3) and (4), where the DC voltage is the limiting factor. 
The maximum current a converter unit can handle, is calculated with the assumption that the converter unit can provide nominal apparent power at the lowest AC voltage it is designed for [2]. Hence, the nominal apparent power of the converter unit is set to 1 p.u. and the lowest $\mathrm{AC}$ voltage is set to 0.8 p.u., and consequently the maximum current is 1.25 p.u.

The converter units electronics and transformer cause losses. Assuming inverter mode operation according to [2], the losses can be modelled as a second order polynomial according to equation (8), depending on the converter AC current, equation (7). The quadratic term and linear terms represents the current dependent losses and the constant term in (8) represents the no-load losses of the converter $[1,2]$. Furthermore, losses caused when the converter unit is operating in rectifier mode are assumed to be $10 \%$ less compared to inverter mode operation, and losses caused by harmonics are neglected [1,2].

The p.u. losses of a converter unit are according to [2,3] assumed to be independent of the converter rating.

$$
\begin{aligned}
& S_{A C_{j_{s w}}} \leq U_{A C_{j_{s w}}} \cdot I_{\max } \\
& S_{A C_{j_{s w}}}^{2}=P_{o u t, A C_{j_{s w}}}^{2}+Q_{o u t, A C_{j_{s w}}}^{2} \\
& P_{i n, D C_{j_{s w}}} \geq-I_{\max } \cdot U_{D C_{j_{s w}}} \\
& P_{i n, D C_{j_{s w}}} \leq I_{\max } \cdot U_{D C_{j_{s w}}} \\
& Q_{o u t, A C_{j_{s w}}} \geq-U_{A C_{j_{s w}}} \cdot I_{\max } \\
& Q_{o u t, A C_{j s w}} \leq U_{A C_{j_{s w}}} \cdot I_{\max } \\
& I_{o u t, A C_{j_{s w}}}=\frac{S_{A C_{j_{s w}}}}{U_{A C_{j_{s w}}}} \\
& P_{i n v_{j s w}}=0.0135 \cdot I_{o u t, A C_{j_{s w}}}^{2}+0.0097 \cdot I_{o u t, A C_{j s w}}+0.015 \\
& P_{\text {rect }_{j s w}}=\left(0.0135 \cdot I_{o u t, A C_{j s w}}^{2}+0.0097 \cdot I_{o u t, A C_{j_{s w}}}+0.015\right) \cdot 0.9
\end{aligned}
$$

The direction of the active power flow through the converter will impose the operating state of the converter. The binary variable $\alpha$ is used to model the operating state of the converter where 1 means inverter operation and 0 means rectifier operation, c.f. equations (10) and (11).

The converter no-load losses contributes significantly to the system losses, unless the converter unit is turned off. Thus, the unit commitment is modelled by the binary variable $\gamma$, and the converter unit is turned off when $\gamma$ is valued zero, c.f. equations (12)-(19). Assuming maximum current through the converter unit $\left(I_{\max }\right)$ and inverter operation mode, the maximum losses can be calculated by equation (8). Furthermore, equations (20)-(23) ensures that the right loss function used, when the converter is either rectifying or inverting. 
Table 1 describes the variables and parameters used.

$$
\begin{aligned}
P_{\text {out }, A C_{j_{s w}}} & \leq P_{\max } \cdot \alpha_{j_{s w}} \\
P_{\text {out }, A C_{j_{s w}}} & \geq-P_{\max } \cdot\left(1-\alpha_{j_{s w}}\right) \\
P_{\text {out }, A C_{j_{s w}}} & \leq P_{\max } \cdot \gamma_{j_{s w}} \\
P_{\text {out }, A C_{j_{s w}}} & \geq-P_{\max } \cdot \gamma_{j_{s w}} \\
Q_{\text {out }, A C_{j_{s w}}} & \leq Q_{\max } \cdot \gamma_{j_{s w}} \\
Q_{\text {out }, A C_{j_{s w}}} & \geq-Q_{\max } \cdot \gamma_{j_{s w}} \\
S_{A C_{j_{s w}}} & \leq S_{\max } \cdot \gamma_{j_{s w}} \\
P_{i n, D C_{j_{s w}}} & \leq P_{\max } \cdot \gamma_{j_{s w}} \\
P_{i n, D C_{j_{s w}}} & \geq-P_{\max } \cdot \gamma_{j_{s w}} \\
P_{s w_{j_{s w}}} & \leq P_{\mathrm{L}, \max } \cdot \gamma_{j_{s w}} \\
P_{s w_{j_{s w}}} & \geq P_{i n v_{j_{s w}}}-P_{\mathrm{L}, \max } \cdot\left(2-\alpha_{j_{s w}}-\gamma_{j_{s w}}\right) \\
P_{s w_{j_{s w}}} & \leq P_{i n v_{j_{s w}}}+P_{\mathrm{L}, \max } \cdot\left(2-\alpha_{j_{s w}}-\gamma_{j_{s w}}\right) \\
P_{s w_{j_{s w}}} & \leq P_{r e c t_{j_{s w}}}+P_{\mathrm{L}, \max } \cdot\left(1+\alpha_{j_{s w}}-\gamma_{j_{s w}}\right) \\
P_{s w_{j_{s w}}} & \geq P_{r e c t_{j_{s w}}}-P_{\mathrm{L}, \max } \cdot\left(1+\alpha_{j_{s w}}-\gamma_{j_{s w}}\right)
\end{aligned}
$$

\subsection{Unified AC/DC loadflow}

In the investigation of the HVDC feeder solution, a unified AC/DC power flow $[6,7]$ approach is chosen to find the optimal power flows that minimize the overall active power losses. The converter has two nodes, an AC node and a DC node.

The slack bus of the system, which represents a large three phase to DC converter connecting the system to the public grid, is a DC node and supplies the power demand. Furthermore, in one of the converters the reference angle is set to zero on the AC side.

The AC/DC connection of the converters, including the converter losses, is described by

$$
P_{i n, D C_{j_{s w}}}-P_{\text {out }, A C_{j_{s w}}}-P_{s w_{j_{s w}}}=0 .
$$

The details of the unified AC/DC load flow used can be found in $[1,8]$.

\subsection{Classical model}

To obtain the power flows, both in the centralized system and decentralized system, the classical model describing the relation between the public grid and the railway grid interconnected by rotary converters is used.

The classical model is presented in $[4,5,8]$, where the converter losses and harmonics are neglected. Using the classical model, both the CS and DS is 
Table 1: Descriptions of the denotations.

\begin{tabular}{ll}
\hline Denotation & Description \\
\hline$S_{A C_{j_{s w}}}$ & apparent power at converter AC side, (variable) \\
$P_{i n, D C, j_{s w}}$ & active power input at converter DC side, (variable) \\
$Q_{o u t, A C, j_{s w}}$ & reactive power output at converter AC side, (variable) \\
$P_{\text {out }, A C, j_{s w}}$ & active power output at converter AC side, (variable) \\
$U_{A C, j_{s w}}$ & voltage at converter AC side, (variable) \\
$P_{\max }$ & maximum power, (parameter) \\
$I_{\max }$ & maximum current, (parameter) \\
$P_{\mathrm{L}, \max }$ & maximum loss of a converter unit (parameter) \\
$U_{D C, j_{s w}}$ & voltage at converter DC side, (variable) \\
$P_{i n v, j_{s w}}$ & inverter loss function, (variable) \\
$P_{r e c t, j_{s w}}$ & rectifier loss function, (variable) \\
$P_{s w, j_{s w}}$ & converter loss function, (variable) \\
$\gamma_{j_{s w}}$ & unit commitment variable, (binary variable) \\
$\alpha_{j_{s w}}$ & direction of flow variable, (binary variable) \\
$j_{s w}$ & the index of the converter \\
\hline
\end{tabular}

described by a Constrained Non-Linear System of Equations (CNS), which is solved in GAMS with the solver CONOPT.

\section{Case studies}

The Swedish inspired test systems are assumed to be in steady state. The locomotives are assumed to either consume or regenerate $4 \mathrm{MW}$ in all cases. All systems investigated have a total installed apparent power of 20 MVA. However, the decentralized system with BT catenary system has a total installed power of 40 MVA due to high transmission losses, and Train III consumption in this case is reduced by $4 \%$ when the power factor is 0.8 in order to obtain feasible solution for the system.

The DC cable used has a resistance of $0.1175 \Omega / \mathrm{km}$, and the voltage is \pm 60 $\mathrm{kV}[2,8]$.

The OCL used in the study are:

- $0.0335+0.031 j \Omega / \mathrm{km}$ for OCL with AT [4].

- $0.2+0.21 j \Omega / \mathrm{km}$ for OCL with BT [4].

The HVDC systems that are studied are:

- 5 MVA converters, placed at a distance of $33 \mathrm{~km}$ from each other, see Figure 3.

- 2 MVA converters, placed at a distance of $11 \mathrm{~km}$ from each other, see Figure 4. 
The systems studied have a length of $100 \mathrm{~km}$ and there are four trains in total of which one is braking in each system, given by Table 2 and Figure 3.

Table 2: Actions of the trains.

\begin{tabular}{ccl}
\hline Train & Number of locomotives & Action \\
\hline I & 1 & consuming (inductive load) \\
II & 1 & regenerating (capacitive load) \\
III & 2 & consuming (inductive load) \\
IV & 1 & consuming (inductive load) \\
\hline
\end{tabular}

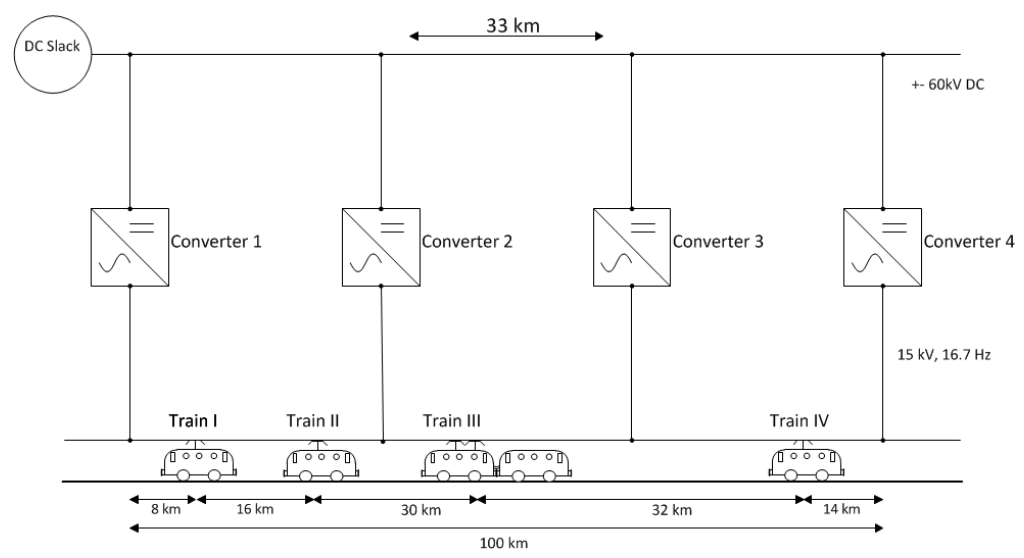

Figure 3: Studied traffic situation with 5 MVA converters.

\section{Results}

The transmission losses in the decentralized BT test system are $11 \%-32 \%$ of the transmitted power, depending on the power factors at the trains, cf. Table 3. Using an OPF controlled HVDC solution with 5 MVA converter, the transmission losses are $4 \%-7 \%$ of the transmitted power. The transmission losses have been reduced by approximately $70 \%-80 \%$. However, the transmission losses are further reduced if densely installed converters of $2 \mathrm{MVA}$ are used. The transmission losses are then $2.1 \%-4.3 \%$. For trains with a power factor of 0.8 , the HVDC 5 MVA OPF controlled HVDC solution can maintain acceptable voltage levels at the train locations. However, according to [9], Train III would have a slightly reduced tractive force, since the train needs $14.5 \mathrm{kV}$ at the OCL for full tractive force. Both 


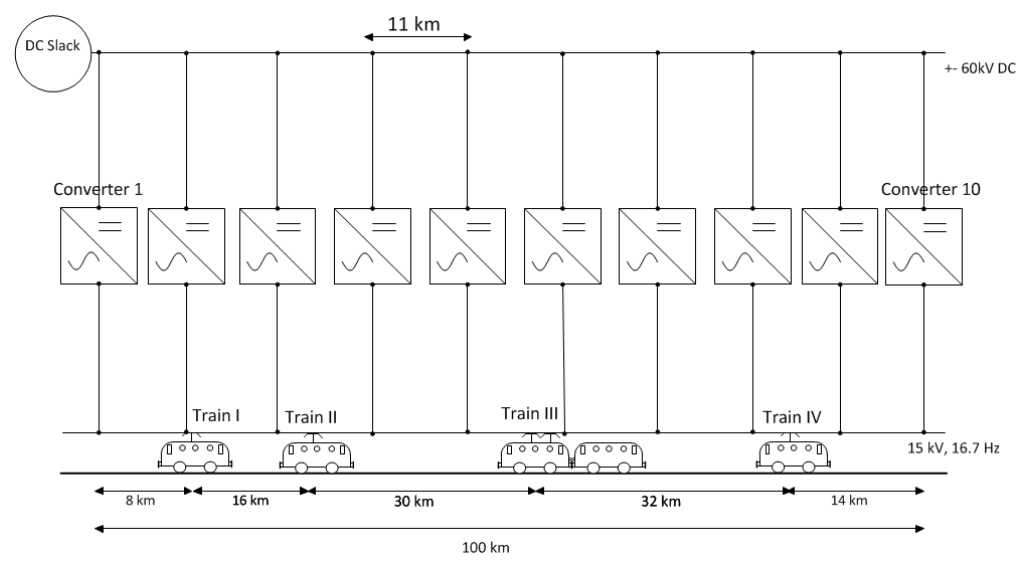

Figure 4: HVDC feeder solution with 2 MVA converters.

Table 3: Transmission losses for the four types of supply systems with BT, [MW].

\begin{tabular}{ccccc}
\hline PF at train & HVDC 2 MVA & HVDC 5 MVA & Centralized & Decentralized \\
\hline $\cos \phi=1$ & 0.3440 & 0.6813 & 1.1615 & 2.4300 \\
$\cos \phi=0.9$ & 0.4700 & 0.9327 & 1.6330 & 4.8400 \\
$\cos \phi=0.8$ & 0.7280 & 1.3275 & 2.2620 & 7.3000 \\
\hline
\end{tabular}

the OPF controlled HVDC systems can maintain a better voltage level at train location in contrast to the decentralized system, where the voltage drops would affect the trains tractive performance and Train III would not produce any tractive force [9]. Having an OCL AT system, the transmission losses are reduced for all

Table 4: Voltages $[\mathrm{kV}]$ at trains $\cos (\phi)$ of 0.8 , OCL with BT.

\begin{tabular}{c|cccc}
\hline System & Train I & Train II & Train III & Train IV \\
\hline HVDC 2 MVA & 16.4 & 16.5 & 16.2 & 16.3 \\
HVDC 5 MVA & 16.1 & 16.8 & 14.2 & 15.2 \\
Centralized & 15.9 & 16.3 & 13.0 & 14.5 \\
Decentralized & 15.1 & 13.8 & 8.3 & 12.9 \\
\hline
\end{tabular}

four systems. The transmission losses of the decentralized system are $2 \%-3 \%$. The OPF controlled HVDC feeder solution with 5 MVA converters have transmission losses of $0.9 \%-1.4 \%$. The transmission losses of the centralized solution are $1.1 \%$ $1.7 \%$, and the benefits from a HVDC feeder OPF solution is not obvious for short 
distances between converters. If a 2 MVA converters are used, the transmission losses are $0.43 \%-0.75 \%$.

The voltage levels, as seen in Table 5, when the trains are operating at power factor 0.8 are acceptable for all four system. Since the voltage levels are above the nominal value of $15 \mathrm{kV}$.

Table 5: Voltages $[\mathrm{kV}]$ at trains with $\cos (\phi)$ of 0.8 , OCL with AT.

\begin{tabular}{c|cccc}
\hline System & Train I & Train II & Train III & Train IV \\
\hline HVDC 2 MVA & 16.4 & 16.5 & 16.2 & 16.3 \\
HVDC 5 MVA & 16.4 & 16.5 & 16.1 & 16.2 \\
Centralized & 16.2 & 16.2 & 15.8 & 15.9 \\
Decentralized & 16.0 & 15.9 & 15.4 & 15.7 \\
\hline
\end{tabular}

Table 6: Detailed losses [MW] of the HVDC feeder solutions, with $\cos (\phi)$ of 1 .

\begin{tabular}{c|ccc|c}
\hline Type of converter \& OCL & AC & DC & Converter & Total \\
\hline 2 MVA, AT & 0.0700 & 0.0320 & 0.4340 & 0.5360 \\
2 MVA, BT & 0.3440 & 0.0340 & 0.4500 & 0.8280 \\
5 MVA, AT & 0.1524 & 0.0273 & 0.4452 & 0.6249 \\
5 MVA, BT & 0.6813 & 0.0321 & 0.5163 & 1.2298 \\
\hline
\end{tabular}

The detailed losses of the HVDC systems with BT and AT are shown in Table 6. Compared to an OCL with AT, the converter losses with BT have increased $3.7 \%$ with 2 MVA converters and $15 \%$ with 5 MVA converter.

Both with AT and BT at the OCL, the distance between the converters is of importance. If smaller and denser distributed converters are used, the AC transmission losses are reduced by approximately 50\%, due to less distance between converter units and better voltage at train locations.

\section{Conclusions and future work}

The results presented in the paper shows some of the advantages of the OPF controlled HVDC feeder solution, and gives a theoretical upper bound on how much losses can be reduced for OCL with AT:s or BT:s. The ability to control the power flows in the system results in reduced transmission losses and indirectly better voltage levels at the train locations, compared to the existing solutions where there is no such ability. 
The comparison between the centralized feeder system layout and the HVDC feeder solution may be unfair, since in reality the high voltage transformers used have ratings of $16 \mathrm{MVA}$ and $25 \mathrm{MVA}$, and are normally placed at longer distances from each other than the $33 \mathrm{~km}$ in used the cases investigated. However, the HVDC feeder OPF solution still performs better than the centralized feeder system solution, when power factors at the trains starts to decrease. In certain cases the total active power losses of the OPF controlled HVDC feeder were less than the transmission losses of the centralized and decentralized feeder solutions, where the conversion losses of the rotary converter were neglected.

In all, the OPF controlled HVDC feeder solution offers many advantages, however, more studies are needed to investigate other aspects, such as dynamics and economical potential.

\section{References}

[1] Abrahamsson, L., Östlund, S. \& Söder, L., OPF Models for Electric Railways Using HVDC. International Conference on Electrical Systems for Aircraft, Railways and Ship Propulsion, 2012. Accepted for publication.

[2] Abrahamsson, L., Kjellqvist, T. \& Östlund, S., HVDC Feeder Solution for Electric Railways. IET Power Electronics, 2012. Accepted for publication.

[3] Kjellqvist, T., On Design of a Compact Primary Switched Conversion System for Electric Railway Propulsion. Ph.D. thesis, Royal Institute of Technology, Electrical Engineering, Electrical Machines and Power Electronics, 2009.

[4] Abrahamsson, L., Railway Power Supply Models and Methods for Longterm Investment Analysis, 2008. Royal Institute of Technology, Electric Power Systems, Trita:2008:036.

[5] Olofsson, M., Optimal operation of the Swedish electrical railway system. Ph.D. thesis, Royal Institute of Technology, 1996, Trita-EES-9601.

[6] Ding, Q. \& Zhang, B., A new approach to AC/MTDC power flow. Advances in Power System Control, Operation and Management, 1997. APSCOM-97. Fourth International Conference on (Conf. Publ. No. 450), volume 2, pp. 689694 vol.2, 1997.

[7] Yu, J., Yan, W., Li, W. \& Wen, L., Quadratic models of AC-DC power flow and optimal reactive power flow with HVDC and UPFC controls. Electric Power Systems Research, 78(3), pp. 302-310, 2008.

[8] Laury, J., OPF for an HVDC Feeder Solution for AC Railways. Master's thesis, School of Electrical Machines and Power Electronics, Royal Institute of Technology, Sweden, 2012.

[9] Biederman, N., Criteria for the Voltage in Rail Power Supply Systems. Orginal title: Utvärderingskriterier för Spänningen $i$ Banmatningsnät. Master's thesis, Kungliga Tekniska Högskolan, Skolan för elektro- och systemteknik, Avdelningen för Elektriska maskiner och Effektelektronik, 2009. 